\title{
The effect of Iran's health transformation plan on utilization of specialized outpatient visit services: An interrupted time series
}

\author{
Bakhtiar Piroozi ${ }^{1}$, Amirhossein Takian ${ }^{2,3,4}$, Ghobad Moradi*1, Mohammad Amerzadeh ${ }^{2}$, Hossein Safari ${ }^{5}$, \\ Obeidollah Faraji ${ }^{1}$
}

Received: 28 Nov 2017

Published: 5 Dec 2018

\section{Abstract}

Background: Health Transformation Plan (HTP) has been one of the biggest reforms in Iran's health system over the past 3 decades. The plan has been implemented since May 2014 and includes several packages that can affect the utilization of health care services. We aimed to assess the effect of implementation of HTP on utilization of specialist outpatient visit rate in clinics affiliated to university hospitals.

Methods: We chose Kurdistan province to collect monthly specialist outpatient visit data for 50 months because this province was not a patient referral hub. An interrupted time series (ITS) analysis and segmented regression analysis were used to evaluate the effects of HTP on specialist outpatient visit rates. Statistical analyses were conducted using STATA version 13.

Results: A significant increase was observed in the specialist outpatient visit rate (12.1 outpatient visit per 1000 population) in the first month after the implementation of HTP $(p=0.000,95 \% \mathrm{CI}=6.36-17.83)$. Also, after the implementation of HTP, a significant increase was observed in the monthly trend of specialist outpatient visit rate equivalent to about 0.53 every month per 1000 population compared to the monthly trend in specialist outpatient visit rate before the intervention $(p=0.033,95 \% \mathrm{CI}=0.04-1.01$ ).

Conclusion: HTP has significantly increased the specialist outpatient visit rate in clinics affiliated to university hospitals in Kurdistan province. Thus, it is necessary to perform some comprehensive studies on all public, private, and semi-private sectors in different parts of the country to provide a better and more comprehensive picture of the effects of HTP on utilization of specialist outpatient visit services.

Keywords: Utilization, Health system reform, Outpatient, Outpatient health service, Clinic visit

Conflicts of Interest: None declared

Funding: Kurdistan University of Medical Sciences

\section{*This work has been published under CC BY-NC-SA 1.0 license.}

Copyright $\odot$ Iran University of Medical Sciences

Cite this article as: Piroozi B, Takian A, Moradi Gh, Amerzadeh M, Safari H, Faraji O. The effect of Iran's health transformation plan on utilization of specialized outpatient visit services: An interrupted time series. Med J Islam Repub Iran. 2018 (5 Dec);32:121. https://doi.org/10.14196/mjiri.32.121

\section{Introduction}

The main point behind health services utilization is to create access to health services for those who are in need $(1,2)$. Receiving and using health services is called health care utilization, and access to health services is the concept of opportunity and ability to use services. This definition is a reflection of the theory that there should be a set of conditions through which a person who is in need of health services can use those services $(3,4)$.

Corresponding author: Dr Ghobad Moradi, moradi_gh@yahoo.com

1. Social Determinants of Health Research Center, Research Institute for Health Development, Kurdistan University of Medical Sciences, Sanandaj, Iran

2. Department of Health Services Management and Economics, School of Public Health, Tehran University of Medical Sciences, Tehran, Iran

3. Department of Global Health \& Public Policy, School of Public Health, Tehran University of Medical Sciences, Tehran, Iran

4. Deputy for Research, Health Equity Research Centre, Tehran University of Medical Sciences, Tehran, Iran

5. Health Promotion Research Center, Iran University of Medical Sciences, Tehran, Iran
Financial, geographic (physical and time distance to service provider), cultural (acceptability), and availability (service delivery, waiting time, availability of qualified providers, right technology) constitute the 4 main dimensions of access. Access to health services has a positive impact on health services utilization. Thus, health system policy-makers should try to improve these dimensions to increase the services utilization. Since health utilization is

$\uparrow$ What is "already known" in this topic:

In Iran, no study has ever been done to assess the effect of implementation of HTP on utilization of specialist outpatient visit services.

\section{$\rightarrow$ What this article adds:}

The implementation of HTP has significantly increased the utilization of specialist outpatient visit services in university hospitals. 
a complex issue and influenced by several factors, a structural change may lead to a sudden change in utilization behavior (5-7).

Universal health coverage (UHC) is an important step towards utilization of health services. UHC has 3 dimensions: covered costs, covered services, and covered individuals. However, the desired quality of health services can be considered as the fourth aspect (8). The ultimate goal of UHC is to benefit everyone from essential health services without enduring financial risk or becoming poor because of health care expenditures (8-10).

There has been a rising interest in moving towards universal health coverage in the recent years. Most of the countries that have achieved UHC are high-income countries and a member of Organization for Economic Cooperation and Development (OECD). However, some lowincome countries, such as Chile, Brazil, Thailand, Mexico, and Turkey, have also moved towards UHC (11-16). Iran has also been working to achieve UHC over the past 2 decades, but reaching this goal has been postponed because of some challenges: low contribution and instability of health system resources due to economic crises, lack of a transparent and efficient tax system, and the impact of fluctuations on oil prices. However, the only determining factor to achieve UHC is not the economic conditions of countries (17).

Iran's health system has started a series of reforms called "Health Transformation Plan" since May 2014. HTP focuses on 3 approaches: provision of access to health services, financial protection of people, and promotion of quality of services. So far, various packages have been implemented based on these 3 phases (18). Some of these packages, which can- directly or indirectly- affect the utilization of outpatient and inpatient health services, are as follow:

- Insuring Iranians with no basic health insurance for free

- Encouraging and supporting the retention of physicians in deprived areas to increase people's access to health care services in the second and third levels by offering incentive payments to the physicians depending on the extent of underdevelopment of the region

- A 24-hour presence of resident specialist physicians in university hospitals to provide timely utilization of health care services

- Improving the quality of visiting services in university hospitals through increasing the motivation of physicians and keeping them in public sector, increasing their willingness to work in hospitals' specialist clinics, maintaining and increasing the number of full-time faculty members in university hospitals, standardizing visit times, and improving the quality of outpatient care services

After implementing this package, medical tariffs for full-time physicians working in outpatient clinics of hospitals are calculated twice the amount of the public sector tariffs taking into account the standards of visit time, creating an outpatient medical record, and keeping accurate records of patient's medical history and measures taken for the patients. To avoid any increase in out-of-pocket payment for patients, this incentive tariff is paid by basic insurance organization. However, this does not include physicians who work in private sectors.

- Also, due to implementation of the first phase of HTP, private activity for physicians in service ( $\mathrm{K}$ coefficient physicians) is prohibited and these physicians must be hired full-time by university hospitals. Moreover, incentive tariffs are considered to increase the incentive of these physicians and other physicians (faculty and nonfaculty members) who are hired full-time by university and do not work in private sector. This incentive tariff is paid by a basic insurance organization to prevent a rise in out-of-pocket payments for patients (19).

Measures taken in the framework of HTP, especially those undertaken during the first phase, can affect the dimensions of access to health services and subsequently the utilization of health services. This study seeks to answer the following question:

How the implementation of HTP has affected the specialist outpatient visit rate in university hospitals?

\section{Methods}

In this study, interrupted time series was used to investigate the short-term (in the first month) and long-term effects of the HTP (intervention) on specialist outpatient visit rate. In interrupted time series, measurements are made periodically from the dependent variable before and after the intervention. Interrupted time series design does not require the control group to create causal relationship between the intervention and the outcome. It is the strongest type of quasi-experimental studies to assess the shortterm and long-term effects of one or more interventions $(20,21)$.

We assumed that the interventions of HTP have more effects on utilization of health care services in provinces where the economic level of the household is weaker. We also needed to choose provinces that would not be the referral hub for other provinces; and Kurdistan province had these criteria. This province is located in west of Iran with the population of 1603011 (22). The studied community included all patients who used specialist outpatient visits in hospitals affiliated to Kurdistan University of Medical Sciences from March 21, 2012 to May 21, 2016. This province has 11 university hospitals.

In this study, outpatient visit services include specialist visits provided to outpatients in the clinics of hospitals affiliated to Kurdistan University of Medical Sciences under the title of "Specialist Clinic". These clinics include infectious disease, neuropsychology, ophthalmology, anesthesia, neurology, dermatology, orthopedics, internal, oncology, lung, surgery, cardiology, obstetrics and gynecology, ENT, nephrology, and nutrition clinics. In this study, the sample size consisted of 50 monthly observations ( 25 observations before implementation of HTP and 24 after the initiation of HTP). HTP was already implemented for observation No. 26. The data for this study were obtained from the center of statistics of the studied hospitals. To eliminate the impact of population growth on utilization of services, the frequency of outpatient service utilization was divided by the population under study.

In addition, a segmented regression analysis was used to 
analyze the time series data. The segmented regression fits the regression model by ordinary least squares (OLS). We used the Newey-West approach in our estimation. This model estimates the coefficients of OLS regression and produces Newey-West standard errors to handle autocorrelation and possible heteroskedasticity $(18,24)$.

In time series, changes in the dependent variable of the intervention are divided into 2 general categories: changes in level and changes in slope. A change in the level indicates a quick or short-term change (in the first month after the intervention) and the change in slope (monthly trend) represents a long-term change in the dependent variable $(23,24)$.

The regression model used to estimate the effect of HTP on outpatient visit services utilization in specialized clinics of Kurdistan University of Medical Sciences is as follows (Equation 1):

$\mathrm{Yt}=\beta 0+\beta 1$ timet $+\beta 2$ interventiont $+\beta 3$ time after intervention $+\varepsilon t$

where $\mathrm{Yt}$ is outpatient visit rate in month $\mathrm{t}$; time represents time in months at time $t$ from the start of the observation period; intervention is a dummy (indicator) variable representing the intervention (pre-HTP period is 0 , otherwise is 1), which was implemented at month 26 in the series, and time after intervention is counting the number of months after the implementation of HTP at time $t ; \beta 0$ represents the intercept or starting level of the outpatient visit rate; and $\beta 1$ is the slope of outpatient visit rate until the implementation of HTP. $\beta 2$ represents the changes in the level of outpatient visit rate in the period immediately following the implementation of HTP (compared to the counterfactual); and $\beta 3$ represents the difference between pre- and post-HTP slopes of outpatient visit rate.

In this study, stationary of residuals was tested using Dickey- Fuller test and it showed that the residuals were stationary $(p=0.049)$. The Newey with one lag was also used to estimate the coefficients of the model. To ensure that we estimated a model that accounted for the correct autocorrelation, we used the actest with lags (12). Autocorrelation was seen just at lag 1 but not at any higher lag orders. Thus, the initial model correctly accounted for this autocorrelation (24). Also, residuals normality was tested and found to have a normal distribution (20-18). All data were analyzed using STATA version 13.

\section{Results}

Regression results are presented in Table 1 . In the beginning of the study, the average rate of monthly specialist outpatient visit was 17.94 per 1000 population. The specialist outpatient visit rate had increased by 0.16 every month per 1000 population before. However, the increase in specialist outpatient visit rate was not statistically significant ( $\mathrm{p}=0.160,95 \% \mathrm{CI}=0.066-0.391)$. Nonetheless, in the first month after the implementation of HTP (short effect), there was a significant increase in the specialist outpatient visit rate (12.096 visit rate per 1000 population, $\mathrm{p}<0.001)$. Also, the difference in the monthly trend of specialist outpatient visit rate was significant before and after the intervention $(p=0.033)$. After the implementation of HTP, a significant increase, equivalent to about 0.53 every month per 1000 population, was seen in the specialist outpatient visit rate (compared to the monthly trend of specialist outpatient visit rate before the intervention) in university hospitals (Table 1).

Table 1. Estimated coefficients of segmented regression model for specialist outpatient visits rate per 1000 population in university hospitals in Kurdistan province

\begin{tabular}{|c|c|c|c|c|c|c|}
\hline \multicolumn{7}{|c|}{ Regression with Newey-West standard errors } \\
\hline maximum lag: 1 & \multicolumn{2}{|c|}{ Number of observation $=50$} & $F(3,46)$ & $=112.92$ & \multirow{2}{*}{\multicolumn{2}{|c|}{$\frac{\mathrm{p}=0.0000}{[95 \% \text { Conf. Interval }]}$}} \\
\hline Parameter & Coefficients & Newey-West Std. Err. & $\mathrm{T}$ & $\mathrm{p}$ & & \\
\hline Intercept & 17.942 & 1.303 & 13.76 & 0.000 & 15.318 & 20.566 \\
\hline Preintervention slope & 0.162 & 0.113 & 1.43 & 0.160 & -0.066 & 0.391 \\
\hline Change in intercept & 12.096 & 2.849 & 4.25 & 0.000 & 6.361 & 17.832 \\
\hline Change in slope & 0.532 & 0.241 & 2.20 & 0.033 & 0.045 & 1.019 \\
\hline
\end{tabular}

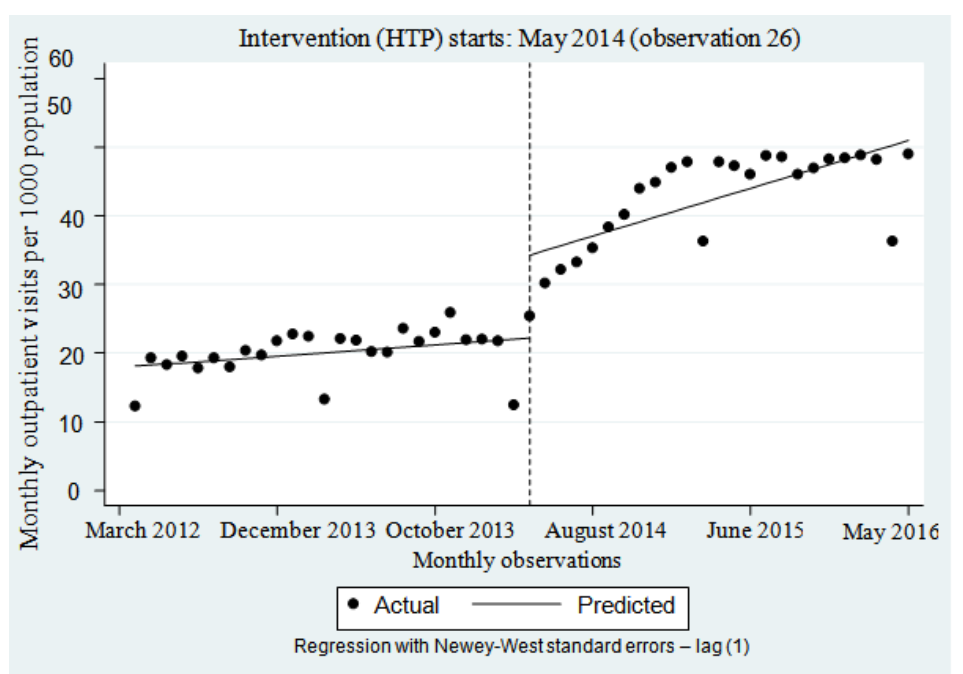

Fig. 1. Segmented regression model of specialist outpatient visit rate per 1000 population in university hospitals in Kurdistan province with Newey-West standard errors 
The visual display for specialist outpatient visit rate per 1000 population before and after HTP in university hospitals in Kurdistan province is as follows (Fig. 1).

\section{Discussion}

Our findings showed that implementation of HTP resulted in a statistically significant increase in specialist outpatient visit rate in hospitals affiliated to Kurdistan University of Medical Sciences. The specialist outpatient visit rate increased by 12.096 visits per 1000 population in the first month after HTP. Also, monthly trend of specialist outpatient visit rate increased by 0.591 per 1000 population compared to the period before implementation of HTP. Increase in the specialist outpatient visit rate can be attributed to a reduction in the cost of outpatient visits in the university hospitals, providing free basic health insurance for people without insurance, longer retention of specialist physicians in the university hospitals, increased patient satisfaction, changing hospitals' behavior and willingness to work in university outpatient clinics after the implementation of HTP. Also, after implementation of HTP, some of the physicians, especially those working in deprived regions, could work only in university hospitals and they could not work in private sectors. This could have shifted outpatients from private sectors to outpatient university clinics. In Iran, about $17 \%$ of the population had not been covered by any health insurance in 2010 . However, after implementation of HTP, nearly 11 million people without health insurance were covered by Iran Health Insurance Organization by August 2016. This number was about 360000 for Kurdistan province (25). The positive relationship between health insurance and the possibility of using outpatient services has been confirmed in studies conducted in Iran (2, 26-28). Consistent with our results, the number of specialist outpatient visits in specialist clinics in Khorasan Razavi province increased by $30 \%$ after about 8 months of implementing HTP compared to before HTP implementation (29). A national study was conducted in Kermanshah province to examine the effect of HTP on hospitalization rate. The results indicated that implementation of HTP had significantly increased hospitalization rate in university hospitals and that the decrease in OOP payment could be the reason for this increase. Theoretically, health insurance can have an impact on the use of health services in 2 ways. First, insurance may reduce the cost of health care at the time of purchase, which may lead to more access and use of health services by people. Part of this increase in consumption may be unnecessary and due to the consumer moral hazard. The consumer moral hazard occurs when the insured people request more health services than the uninsured, as the cost of receiving the service is less than the actual cost of the service. Secondly, health insurance may increase the use of health services due to the provider-induced demand (provider moral hazard) (30-33). In general, the money paid by patients influences the volume of services used by them and the volume of services provided by health service providers (31). Some services, such as physician's request for a visit, are highly elastic and having an insurance coverage can increase their use. From the view- point of health policy-makers, one of the main concerns about HTP is provider-consumer moral hazard (34). Therefore, the increase in the specialist outpatient visits rate may be divided into 2 parts. One includes meeting unfulfilled real needs that previously existed due to lack of access to these services (pre-existing unmet need) that are now fulfilled because of implementation of HTP; and the other includes unnecessary services due to providerconsumer moral hazard. The findings of Rand study showed that the price elasticity for outpatient services is higher than inpatient services (35). The study of Wagaste et al in China confirmed the positive impact of health insurance on using outpatient services (36). Also, Trujillo et al in Columbia revealed that health insurance has had a positive impact on using health services by poor people and those without insurance coverage (37). Also, the initial results of Thai Health Reform Program, known as 30Baht UHC, showed that insurance has increased the access to outpatient health services (38).

\section{Limitations}

This study was conducted only in university hospitals in Kurdistan province, western Iran. Thus, its results cannot be generalized to all provinces of the country. Also, this study investigated the effect of HTP on outpatient visit rate 2 years after HTP implementation, as HTP had been implemented for 2 years at the time of conducting this study. Therefore, it is recommended to consider longer time periods for future studies.

\section{Conclusion}

We found a statistically significant increase in the specialist outpatient visit rate in the first month and monthly trend after HTP implementation in specialist clinics affiliated to Kurdistan University of Medical Sciences. However, it is essential to conduct comprehensive studies on all public, private, and semi-private sectors in different parts of the country to provide a more comprehensive picture of the effects of HTP on utilization of specialist outpatient visit services.

\section{Acknowledgments}

The authors wish to thank the deputy of research of Kurdistan University of Medical Sciences for approving and supporting this research (Grant no. 1395.318).

\section{Conflict of interest}

None declared.

\section{References}

1. Van der Heyden JH, Demarest S, Tafforeau J, Van Oyen H. Socioeconomic differences in the utilisation of health services in Belgium. Health Policy. 2003;65(2):153-65.

2. Motlagh SN, Sabermahani A, Hadian M, Lari MA, Mahdavi MR, Gorji HA. Factors Affecting Health Care Utilization in Tehran. Global J Health Sci. 2015;7(6):240-49.

3. Zhou Z, Gao J, Fox A, Rao K, Xu K, Xu L, Zhang Y. Measuring the equity of inpatient utilization in Chinese rural areas. BMC Health Serv Res. 2011;11(1):201-13.

4. Rezapoor A, Roumiani Y, Azar FE, Ghazanfari S, Mirzaei S, Asiabar AS, Faradonbe SB. Effective factors on utilization and access to 
health care: a population-based study in Kerman. J Health Administ. 2015;18(60):24-35.

5. Beckman A, Anell A. Changes in health care utilisation following a reform involving choice and privatisation in Swedish primary care: a five-year follow-up of GP-visits. BMC Health Serv Res. 2013;13(1):452-61.

6. Hardie NA, Kyanko K, Busch S, LoSasso AT, Levin RA. Health literacy and health care spending and utilization in a consumer-driven health plan. J Health Commun. 2011;16(3):308-21.

7. Habicht J, Kunst AE. Social inequalities in health care services utilisation after eight years of health care reforms: a cross-sectional study of Estonia, 1999. Soc Sci Med. 2005;60(4):777-87.

8. Lagomarsino G, Garabrant A, Adyas A, Muga R, Otoo N. Moving towards universal health coverage: health insurance reforms in nine developing countries in Africa and Asia. Lancet. 2012;380(9845):933-43.

9. Evans DB, Etienne C. Health systems financing and the path to universal coverage. Bull World Health Organ. 2010;88(6):402-3.

10. World Health Organization. World Health Report: health systems financing the path to universal coverage. World Health Organization. 2010 .

11. Boerma T, Eozenou P, Evans D, Evans T, Kieny MP, Wagstaff A. Monitoring progress towards universal health coverage at country and global levels. PLoS Med. 2014;11(9):e1001731.

12. Atun R, Aydın S, Chakraborty S, Sümer S, Aran M, Gürol I, Nazlığlu S, Özgülcü Ş, Aydoğan Ü, Ayar B, Dilmen U. Universal health coverage in Turkey: enhancement of equity. Lancet. 2013;382(9886):65-99.

13. Tangcharoensathien V, Patcharanarumol W, Ir P, Aljunid SM, Mukti AG, Akkhavong K, Banzon E, Huong DB, Thabrany H, Mills A. Health-financing reforms in southeast Asia: challenges in achieving universal coverage. Lancet. 2011;377(9768):863-73.

14. Limwattananon S, Tangcharoensathien V, Tisayaticom K, Boonyapaisarncharoen T, Prakongsai P. Why has the Universal Coverage Scheme in Thailand achieved a pro-poor public subsidy for health care? BMC Public Health. 2012;12(1):6-18.

15. Knaul FM, González-Pier E, Gómez-Dantés O, García-Junco D, Arreola-Ornelas H, Barraza-Lloréns M, Sandoval R, Caballero F, Hernández-Avila M, Juan M, Kershenobich D. The quest for universal health coverage: achieving social protection for all in Mexico. Lancet. 2012;380(9849):1259-79.

16. Marten R, McIntyre D, Travassos C, Shishkin S, Longde W, Reddy $\mathrm{S}$, Vega J. An assessment of progress towards universal health coverage in Brazil, Russia, India, China, and South Africa (BRICS). Lancet. 2014;384(9960):2164-71.

17. Iran National Institute of Health Research. Universal Health Coverage in Iran: Gozinaye Parsiyane Teb. 2015.pp.1-177.

18. Rad EH, Yazdi-Feyzabad V, Yousefzadeh-Chabok S, Afkar A, Naghibzadeh A. Pros and cons of the health transformation program in Iran: evidence from financial outcomes at the household level. Epidemiol Health. 2017;39:e2017029

19. Pirani N, Zahiri M, Engali KA, Torabipour A. Hospital Efficiency Measurement Before and After Health Sector Evolution Plan in Southwest of Iran: a DEA-Panel Data Study. Acta Inform Med. 2018;26(2):106-110.

20. Rashidian A, Joudaki H, Khodayari-Moez E, Omranikhoo H, Geraili B, Arab M. The impact of rural health system reform on hospitalization rates in the Islamic Republic of Iran: an interrupted time series. Bull World Health Organ. 2013;91(12):942-9.

21. Wagner AK, Soumerai SB, Zhang F, Ross-Degnan D. Segmented regression analysis of interrupted time series studies in medication use research. J Clin Pharm Ther. 2002;27(4):299-309.

22. Iran SCo. Iran Statistical Yearbook. Statistical Centre of Iran, Tehran, Iran, 2017.

23. Bernal JL, Cummins S, Gasparrini A. Interrupted time series regression for the evaluation of public health interventions: a tutorial. Int $\mathbf{J}$ Epidemiol. 2017;46(1):348-55.

24. Linden A. Conducting interrupted time-series analysis for single-and multiple-group comparisons. Stata J. 2015;15(2):480-500.

25. Anvar E. Health insurance Organization. TASNIM NEWS. Accessed July 2017. Published November 2016. Available at: https://www.tasnimnews.com/fa/news/1395/08/16/1232181/600.

26. Hassanzadeh J, Mohammadbeigi A, Eshrati B, Rezaianzadeh A. and Rajaeefard, A. Determinants of inequity in health care services utilization in markazi province of iran. Iran Red Crescent Med J. 2013;15(5):363-70.

27. Ahmadi AM, Nikravan A, Naseri A, Asari A. Effective determinants in household out of packet payments in health system of Iran, using two part regression model. J Health Administ. 2014;17(56):7-18.

28. Hosseinpoor AR, Naghavi M, Alavian SM, Speybroeck N, Jamshidi H, Vega J. Determinants of seeking needed outpatient care in Iran: Results from a national health services utilization survey. Arch Iran Med. 2008;11(1):135-42.

29. Ganjifard Mahmoud. Visit to the public clinics increased 30 percent in South Khorasan. Mehr Newsagency. Accessed November 2017. Published December 2014. Available at: http://www.mehrnews. com/news $/ 2438720$.

30. Soofi M, Bazyar M, Rashidian A. Types of moral hazards and its effects on insurance marketing and health system. J Hospital. 2012;11(3):73-80.

31. Dave D, Kaestner R. Health insurance and ex ante moral hazard: evidence from Medicare. Int $\mathrm{J}$ Health Care Finance Econ. 2009;9(4):367-90.

32. Bhattacharya J, Packalen M. The other exante moral hazard in health. J Health Econ. 2012; 31(1):135-46.

33. Zweifel P, Manning WG. Moral hazard and consumer incentives in health care. Handbook of health economics: Elsevier; 2000.pp.40959.

34. Haghparast-Bidgoli H, Saadat S, Bogg L, Yarmohammadian MH, Hasselberg M. Factors affecting hospital length of stay and hospital charges associated with road traffic-related injuries in Iran. BMC Health Serv Res. 2013;13(1):281-92.

35. Liu S, Chollet D. Price and income elasticity of the demand for health insurance and health care services: Mathemat Policy Res. 2006.pp.1-79.

36. Wagstaff A, Pradhan MP. Health insurance impacts on health and nonmedical consumption in a developing country: World Bank; 2005.pp.1-25.

37. Trujillo AJ, Portillo JE, Vernon JA. The impact of subsidized health insurance for the poor: evaluating the Colombian experience using propensity score matching. J Health Care Finance Econ. 2005; 5(3):211-39.

38. Damrongplasit, K. and G.A. Melnick, Early results from Thailand's 30 Baht Health Reform: something to smile about. Health Aff. 2009;28(3):457-66. 